Ricardo Astaburuaga G.

\title{
El agua en las zonas áridas de Chile
}

La discusión por el agua ciertamente irá desplazándose hacia lugares más centrales en el espectro de prioridades mundiales. De no haber cambios radicales en las políticas globales sobre recalentamiento terrestre, consumo y reciclaje, la escasez de agua será una condición independiente de latitudes. ¿Cuál es la lógica de la aridez? ¿cómo es su relación con las lluvias, los ríos y la humedad del aire? ¿cómo interviene en el desarrollo de la cultura? Este texto introduce la relación entre disponibilidad de agua, paisaje, urbanismo y medio ambiente. Palabras clave: Zonas áridas - Chile, urbanismo, recursos hídricos, agua, aguas servidas, sequia.

The debate over water is no doubt destined to become ever more central to the world's priorities. Unless there are radical changes in international policies on global warming, consumption and recycling, the shortage of water will be felt everywhere. What is the logic of aridity, and how does it relate to precipitation, rivers and air humidity? How does it intervene in the development of culture? This article introduces the relationship between water supply, landscape, urbanism and the environment.

Key words: Arid zones - Chile, urbanism, water resources, water waste water, drought.
"Los signos territoriales generan cultura, y viceversa." Prof. Ricardo Astaburuaga Echenique

¿Qué es una zona árida, por qué existen?, ¿cuáles son sus defectos y ventajas?, ¿cómo las manejamos en Chile? Este artículo sólo pretende entregar algunos antecedentes técnicos generales respecto de nuestras zonas áridas, las facilidades y dificultades que presenta su ocupación por asentamientos humanos permanentes, y la forma cómo administramos esta aridez, para terminar destacando la necesidad que el ordenamiento urbano en estas zona, se inicie respetando el poco flexible trazado de las diversas redes hídricas territoriales, a saber, cauces naturales y artificiales, redes de riego y drenaje, y sistemas de reutilización de aguas servidas y excedentes de agua.

\section{Zona árida: precipitación menor que la evapotranspiración vegetal}

Nuestra definición de zona árida está referida a la vegetación que nos es útil: técnicamente se define como aquella región donde la precipitación es usualmente inferior a la evapotranspiración de la vegetación permanente o de los cultivos usuales, entendiendo por ello la cantidad de agua que es capaz de evaporar y transpirar cada planta.

En la zona central de Chile, esta vegetación consume entre 700 y $1.200 \mathrm{~mm} /$ año. De este modo, la zona árida chilena abarca desde el extremo norte del territorio hasta Concepción, incluyendo zonas desérticas (I y II Región) y luego un clima mediterráneo árido (III y IV
Región), semiárido (V y Región Metropolitana) que se va tornando templado hacia el sur, perdiendo esta calidad pasado el río Bio - Bio.

En estas zonas, el agua es el recurso limitante del desarrollo, tanto económico como urbano, y por lo tanto, cualquier mejoramiento permanente en la eficiencia del uso del agua se traduce en un inmediato aumento proporcional de la productividad de la zona.

Por otra parte, una inadecuada distribución mensual de las precipitaciones puede generar zonas muy áridas, dado que la evapotranspiración vegetal (ETo) es mínima en los meses fríos ( $1 \mathrm{~mm} /$ día), y máxima en los meses cálidos (7-15 mm/ día).

Esto acentúa la condición de zona árida en Chile, ya que las precipitaciones se concentran sólo en los tres meses de invierno, de escasa ETo, y los nueve meses restantes son prácticamente de sequía y alta ETo, coincidentes con el crecimiento vegetal.

En zonas no áridas sucede lo contrario: Zambia tiene sólo tres meses secos en un invierno caluroso, en India llueve sólo en verano y en París y Buenos Aires llueve continuamente todo el año. En otras zonas áridas como Arizona, el calor seco y la ETo son altísimos, con algo más de lluvia en verano. Esta gran variedad climática ha generado manejos y soluciones muy propias para cada región, con tecnologías sofisticadas difícilmente exportables.

\section{Los cultivos de las zonas áridas}

Las primeras civilizaciones se desarrollaron

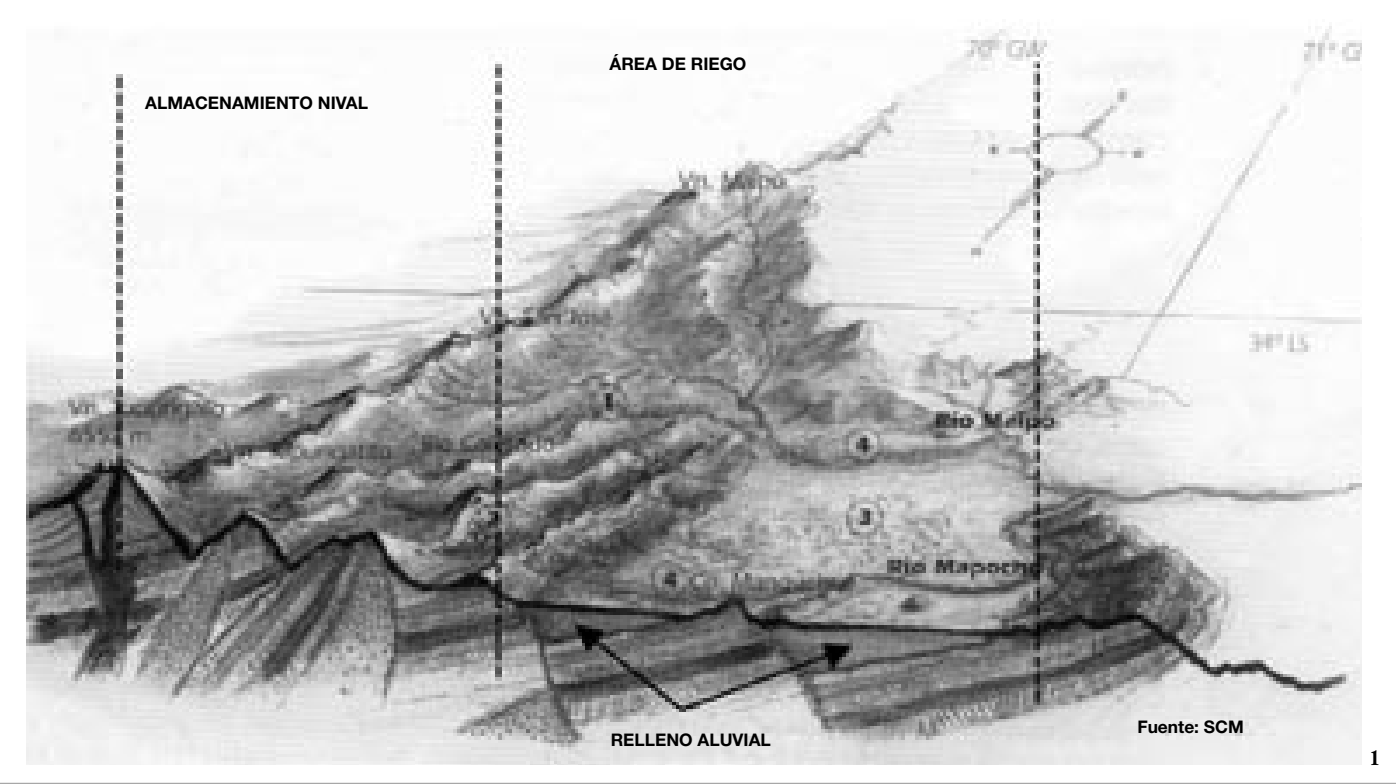


en torno al riego en zonas áridas de clima mediterráneo (Egipto, Mesopotamia, México). La buena combinación de un clima fácil y la necesidad de dividir organizadamente el trabajo -para poder regar los cultivos- estimularon el desarrollo de comunidades organizadas. Además estas civilizaciones, y las que siguieron en el lugar, buscaron y combinaron genéticamente diversas plantas rústicas, generando así la mayor parte de los cultivos que hoy alimentan al mundo (trigo y otros granos, legumbres, nectarinas, etc.).

Como resultado, una gran cantidad de los cultivos que existen crece mejor en su clima de origen: las zonas áridas regadas. El Chile de la conquista y la colonia se benefició de la inmediata adaptación de las semillas mediterráneas y las árabes de África del Norte y del Medio Oriente, que desde un comienzo entregaron altos rindes a diferencia del resto de América (exceptuando algunos valles de Perú, México y California, con clima similar). Las condiciones fitosanitarias y de luminosidad son mejores en climas secos. Los hongos y pestes dificultan los cultivos en zonas húmedas y calurosas.

Sin embargo, como se vio anteriormente, en nuestro país casi toda la evapotranspiración de estos cultivos se produce en un período sin lluvias suficientes, por lo que necesariamente requieren de riego artificial. La tasa de riego tecnificado usual en Chile es de $0,5 \mathrm{l} / \mathrm{seg} /$ ha durante 6 meses, equivalente a $780 \mathrm{~mm}$ al año. Para riego menos tecnificado, empastadas y jardines, esta tasa puede llegar al doble.

\section{Aspectos meteorológicos de Chile y otras zonas áridas}

Las zonas áridas resultan de fenómenos meteorológicos planetarios; se ubican mayoritariamente en ambos trópicos, donde descienden masas de aire seco y frío con altas presiones. En Chile, esto se suma a un continente que interrumpe de polo a polo las corrientes oceánicas y su intercambio térmico, a una alta cordillera que dificulta el intercambio atmosférico, y a la corriente fría de Humboldt, resultando un centro de alta presión permanente en el tiempo y semi-estacionario frente a Antofagasta, denominado anticiclón del Pacífico.

Este centro de alta presión actúa como una barrera, desvía los frentes hacia el sur, generando en su entorno la zona con menos precipitaciones del planeta. Cuando este anticiclón se desplaza un mínimo hacia el norte o norponiente, los frentes logran entrar hacia la III Región, generando las escasas precipitaciones locales.

Dado el movimiento de traslación de la Tierra, el anticiclón se desplaza en forma relativa hacia el sur en verano (empujando a los frentes hacia el paralelo $45^{\circ}$, la zona de Aysén), y hacia el norte en invierno, permitiendo las lluvias de nuestra zona central y su típico clima mediterráneo.

Un fenómeno similar de desplazamiento de anticiclones semi-estacionarios genera los otros escasos climas mediterráneos del planeta, a saber, en California, Sudáfrica, el sur de Australia y el mayor de todos rodeando el mar Mediterráneo. Los frentes que acceden a Chile desde el Pacífico se condensan produciendo camanchaca; primero al encontrarse con la corriente de Humboldt. Luego al ascender sobre la cordillera de la Costa (a $2.500 \mathrm{msnm}$ ), y finalmente al ascender sobre la cordillera de los Andes (a $5.000 \mathrm{msnm}$ ), donde descargan buena parte de su humedad. De este modo, bajan secos y fríos hacia Argentina, generando una vasta zona árida contigua a los Andes. De este modo, en Valparaíso llueve el doble que en Santiago, y en Portillo el doble que en Valparaíso. Este patrón transversal de precipitaciones se atenúa hacia el sur de Chile, y se exagera hacia el norte (descenso norte-sur de la cordillera).

(Las violentas barreras orográficas que Chile antepone a los frentes meteorológicos reducen a la nada a otros estímulos para la precipitación, como son la presencia de bosques, corrientes ascendentes diversas, riego de nubes con yoduro de plata, etc.)

Las sequías y crecidas son fenómenos meteorológicos que normalmente deben ocurrir, y que simplemente se alejan del promedio. En Chile, la causa principal de estos extremos obedece a desplazamientos transitorios del anticiclón del Pacífico, muchas veces motivado por el fenómeno térmico más global El Niño.

\section{Almacenamiento del agua en Chile}

En Chile tenemos todos los años una sequía de 9 meses, lo que es poco común en otras zonas del planeta. Por esto hablo de una sequía permanente, que compensamos principalmente
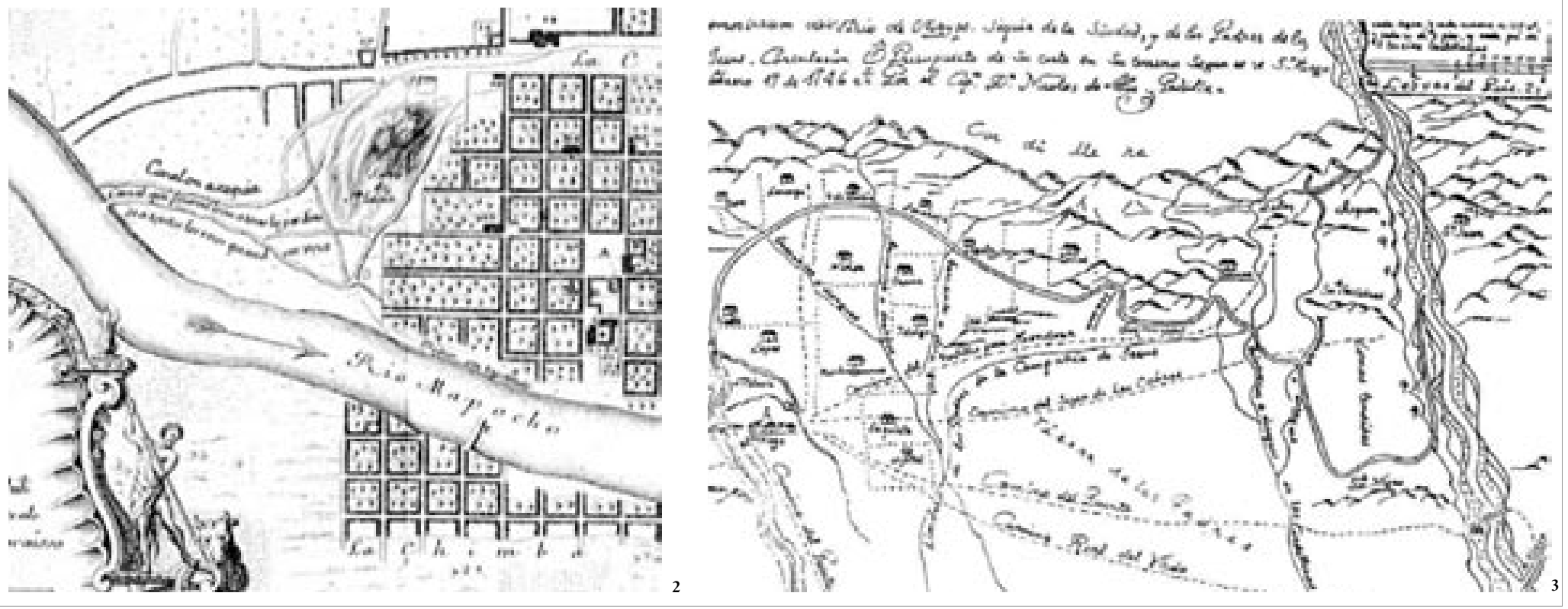


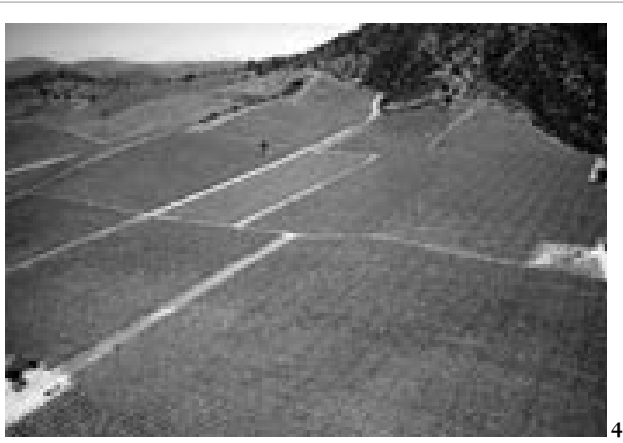

con el almacenamiento nival de la cordillera, más otros almacenamientos de menor envergadura. Almacenamiento nivo - glaciar: Desde el punto de vista del abastecimiento de agua, la cordillera de los Andes es nuestro Nilo. No sólo se produce mayor precipitación en la cordillera que en los valles, sino que ésta queda acumulada para ir derritiéndose gradualmente según la radiación solar, generando ríos estables y abundantes durante los meses secos, con suficiente cota para regar gravitacionalmente los valles. El almacenamiento nival proporciona el agua de primavera y verano de los ríos, y el glaciar desde fines de verano al otoño. Cabe destacar que la superficie cordillerana nival de la zona árida chilena abarca más de un tercio de la superficie total de cada región, constituyendo un almacenamiento de considerable dimensión.

Almacenamiento subterráneo: En Chile no existen grandes embalses subterráneos (como el valle de California), sino acuíferos medianos en el relleno del valle central; en el resto del país, la capacidad de almacenamiento subterráneo de agua es mínima. Los embalses subterráneos bajo el valle central son de gran importancia, ya que sus afloramientos naturales, para desaguar a través de la cordillera de la Costa, realimentan a los ríos, permitiendo así que toda el agua cordillerana sea previamente usada. Estos afloramientos no dependen del grado de humedad de cada año, ya que están regulados por más de diez años de infiltraciones; además, generan zonas húmedas al pie de la cordillera de la Costa, con abundante vegetación mayor (como la zona de Peñaflor). En forma creciente, se están explotando estos acuíferos mediante pozos profundos, mermando los afloramientos naturales.

Almacenamiento en el suelo y capa vegetal: El almacenamiento de agua en el suelo y capa vegetal es del orden de un 10\% del volumen de suelo. Así, una lluvia normal de $15 \mathrm{~mm} /$ día bumedece sólo 15 cm de suelo. A lo largo del invierno, se humedece usualmente no más de $60 \mathrm{~cm}$ de suelo, humedad que tiende a ser evaporada por capilaridad. En Chile, este almacenamiento de agua es importante, ya que abastece de agua a la vegetación en los períodos entre cada lluvia, o entre cada riego. Almacenamientos artificiales: En Chile resulta obvio almacenar artificialmente agua desde los períodos húmedos hacia los secos. Sin embargo, dada la fuerte pendiente de nuestros valles, los muros de embalse resultan muy altos para almacenar poca agua, por lo que este tipo de inversión resulta poco o nada rentable. Los mayores embalses para riego del país se ubican en el Norte Chico (La Paloma), para compensar la permanente secuencia de dos años secos cada cuatro en la región.
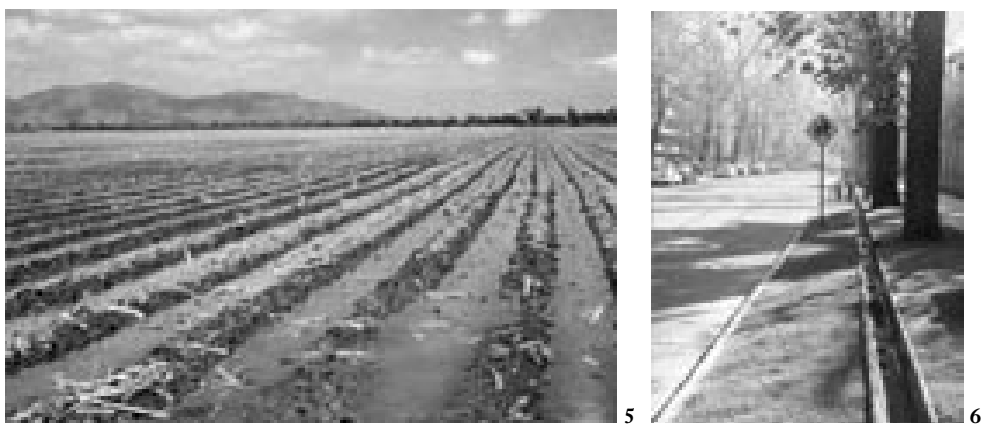

4 Riego por surcos

5 Riego tecnificado

6 Últimas acequias urbanas en

Santiago (Av. Ricardo Lyon)
Régimen de los ríos en Chile

Se llama régimen de un río a sus variaciones estacionales de caudal. Pueden ser de régimen pluvial (máximo caudal en estación lluviosa), nival (máximos en estación de deshielos) o glaciar (parejos, con algún máximo en verano), como sus combinaciones. Desde el punto de vista del riego, en las zonas áridas chilenas se prefieren los ríos de régimen nival o nivo - glaciar, ya que su oferta de caudales coincide con las demandas de riego.

En Chile hablamos de sequía cuando no se produce suficiente acumulación de nieve en la cordillera. Las zonas que no tienen acceso a un almacenamiento nival (por ejemplo, los valles costeros) son muy vulnerables a los años secos. En el Norte Chico, dados los pocos frentes lluviosos que llegan tan al norte, se tienen tres años secos cada cuatro. En la zona central, las grandes sequías son menos frecuentes, últimamente cada 20 años. En Chile las crecidas y aluviones ocasionados por tormentas no generan inundaciones duraderas, dada la fuerte pendiente de nuestros valles. Sin embargo, generan caudales inusuales en los ríos, con el consiguiente arrastre de aquellas piedras que ha ido produciendo la cordillera desde la crecida anterior. Esto ocurre en ríos con lechos muy anchos, configurados no para transportar el agua, sino para las piedras que ingresan (el arrastre es por metro de ancho). Mientras más árida es una zona, sus crecidas son más agresivas, ya que ofrecen más suelo susceptible a la erosión y arrastre pluvial.

Los ríos del norte y centro de Chile muestran un lecho pedregoso (sin suelo fino), suficiente para el paso de su crecida centenaria. Las crecidas no son desproporcionadas en las hoyas nivales (la nieve se queda), y muy agresivas en hoyas pluviales (por ejemplo, el río Mapocho).

\section{Distribución y administración de las aguas}

El agua del Nilo se reparte mediante largos canales - lagunas, que se deprimen cuando se los bombea en exceso, problema similar al de Mesopotamia y al del valle del río Po. Los inmensos canales que riegan terrenos en India son manejados como embalses; la mayor parte de los terrenos regados del mundo tienen mal drenaje, como Holanda, y sus canales deben entregar justo el agua que en cada momento evapora la vegetación: los excesos generan inundaciones difíciles de resolver. California, como Arizona o Israel, se abastece desde pozos. Cada zona de riego ha inventado un sistema de reparto de agua particular, ajustado a muchas variables, y no exportable.

Administración de nuestra sequía permanente Las aguas del país son un bien nacional de uso público, sobre el cual se conceden derechos de aprovechamiento precisos respecto de la fuente de agua, caudal, destino, etc. Prácticamente todo el caudal permanente (80\%) de los ríos de la zona árida chilena ya está concedido a algún usuario, y los nuevos deberán adquirirlos desde los primeros. El reparto de las aguas de cada río opera de la siguiente manera: el total del caudal del río está dividido en un número arbitrario de "acciones" o partes iguales de río. A cada acción le corresponde un porcentaje fijo del caudal total del río en cada instante, medido a la salida de la cordillera (cabecera). Cada propietario de acciones de río elige la forma de cómo conduce su agua a destino (elige un canal de riego, toma propia, bomba, etc.). Un juez de río con atribuciones judiciales, nombrado por el conjunto de los accionistas, vigila diariamente que el reparto entre todas las bocatomas o saques de agua, se ajuste a las acciones que les corresponden. Si el río trae más agua de lo normal, cada canal saca lo que desea. Las excepciones son Pica y el valle del Limarí, que reparten el agua de sus cochas o embalses a su modo. La participación del Estado es escasa: puede conceder nuevas acciones sólo si el caudal permanente disponible lo permite, resuelve técnicamente controversias, y obtiene la estadística de los caudales.

Luego, el reparto del agua entre los diferentes usuarios de cada canal se realiza en proporción a sus acciones, mediante un tipo de obra denominada "marco partidor" (de origen árabe; sólo se usa, perfeccionado, en Chile), reparto administrado por los mismos usuarios mediante la "Asociación de Canalistas", cuyo directorio también tiene atribuciones judiciales para resolver los conflictos internos con gran velocidad y conocimiento de causa, ya que todos los involucrados son locales. Este tipo de administración ha resultado tan eficaz y económica, que pasa inadvertida. En otros países, grandes administraciones son un lastre para todos los usuarios.

Toda la normativa relacionada con el uso, concesión y administración de las aguas terrestres, sus infraestructuras, etc. se encuentra refundida en el Código de Aguas. Este código en general defiende a los usuarios del agua ante amenazas externas como la expansión urbana.

\section{Sistemas de riego}

Los sistemas de aplicación del agua a los suelos agrícolas son muy variados; todos buscan conservar la suficiente humedad en esos suelos, compensando el consumo de agua por ETo del cultivo o vegetación local.

Los antiguos sistemas de riego tendido o por surcos buscan humedecer unos $50 \mathrm{~cm}$ de suelo; 


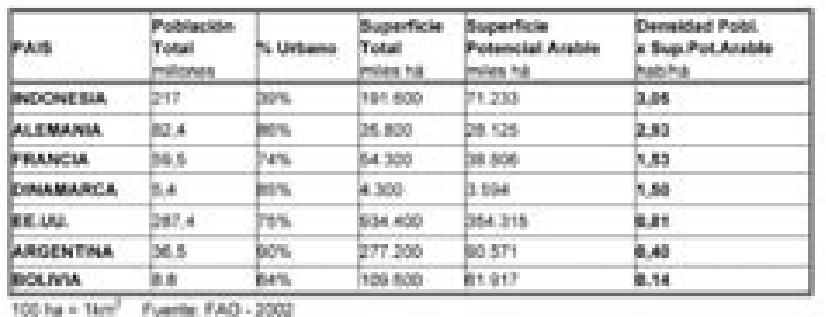

de ellos, los $10 \mathrm{~cm}$ superiores se evaporan rápidamente por capilaridad, y los $40 \mathrm{~cm}$ inferiores abastecen al cultivo por una o dos semanas hasta el riego siguiente. Estos sistemas de aplicación manual presentan el defecto de una muy mala aplicación durante las horas de la noche, con importantes pérdidas de agua, resueltas por los "tranques de noche".

Los actuales sistemas de riego tecnificado (goteo, aspersión, etc.) entregan poca agua al suelo en forma casi continua, especialmente durante la noche, en conjunto con abonos y otros productos, compensando la evapotranspiración. La aplicación del agua es eficiente, a pesar de la mayor evaporación desde la superficie siempre húmeda del suelo, y requieren escasa mano de obra. Su defecto radica en la necesidad de altas presiones de agua dentro de una red de tuberías costosas, y en el desarrollo de raíces confinadas a bulbos húmedos que no siempre abarcan todo el suelo.

\section{Uso histórico de las aguas en Chile}

Acequias urbanas Los indígenas prehispánicos del país fueron principalmente pescadores $\mathrm{y}$ cazadores, sin agricultura de riego, salvo raras excepciones. Los últimos incas introducen escasamente el riego en el valle central, con poblaciones agrícolas alineadas a lo largo de algún canal, que se conservan hoy como "calles largas" (como Curtiduría).

Los primeros españoles detectan hábilmente las ventajas del riego al fundar sus villas, casi siempre en lugares de poca vegetación (con ventaja bélica para sus caballos). Se aseguran previamente de contar con un fácil y seguro abastecimiento de agua desde algún río, el consiguiente canal hasta alcanzar el punto alto de la explanada (generalmente riberano), y luego el damero orientado y ajustado según las pendientes de riego, con cada manzana abastecida por una acequia ya sea por el oriente en sentido norte - sur, o por el norte en sentido oriente poniente, permitiendo hortalizas de riego al interior y alimentando las norias para la bebida. El posterior crecimiento de la villa con casas - huerto siempre fue acompañado por sus acequias, y siguiendo sus trazados posibles.

La ampliación del riego agrícola comenzó así desde la villa hacia sus alrededores: terrenos que, al ser absorbidos después por ésta, ya contaban con una red de acequias que se incorporaban. Hasta fines del siglo XIX, las acequias seguían cumpliendo su función en la mayor parte de las ciudades y pueblos de Chile, y a la vez servían para evacuación de aguas lluvia y alcantarillado (las casitas al fondo del patio), por lo que el agua para la bebida se compraba y guardaba en grandes tinajas de greda. Actualmente, a pesar de la casi total extinción de las acequias urbanas, todavía podemos reconocer la relación entre su trazado y el trazado urbano.

La gran sequía de 1770 y los canales de riego Durante la conquista y la colonia, el riego agrícola se limitó a las zonas urbanas y sus aledaños, más algunos paños de pie de monte vecinos a quebradas. La producción agrícola de trigo, pastos y otros era de rulo. Entre los años 1770 y 1782 se produjo una larga sequía, alternando tres años secos con nueve extremadamente secos; la agricultura de rulo colapsó y buena parte de la cordillera de la Costa central se secó definitivamente (tuvo buenos pastos, bosques y quebradas).

Como consecuencia de esta larga sequía, se inició la construcción del canal San Carlos desde el río Maipo hacia el río Mapocho, para regar las extensas explanadas secas del sur de Santiago. Luego de muchas dificultades, los inmediatos éxitos de esta obra de riego (agrícola, económico y de valor paisajístico) alentó al resto de los agricultores del valle central a construir canales para sus extensos fundos (ellos eran mineros recientemente enriquecidos, que sabían excavar tierra). Muchos quebraron en la empresa, pero en un solo siglo lograron regar nada menos que un millón de hectáreas, casi las mismas que se riegan hoy, y con los mismos canales.

Los anteriores agricultores lograron regar los mejores suelos de la zona árida del país, ubicados relativamente cerca de las fuentes de agua. A inicios del siglo XX, el Estado inicia obras para ampliar la cobertura de riego: obras de mayor envergadura que surten terrenos distantes o de pequeños propietarios que no podían absorber semejante inversión. Paralelamente, construye los pocos embalses anuales existentes en el país; hoy, luego de construir embalses en los ríos Elqui y Huasco, además del canal Laja - Diguillín, el fisco subsidia pequeños proyectos privados de nuevo riego, que en conjunto suman importantes hectáreas de nueva agricultura intensiva.

Dado el actual agotamiento de las aguas superficiales respecto de nuevos derechos de agua, el reciente crecimiento del riego se abastece desde las aguas subterráneas, mediante pozos profundos. $\mathrm{El}$ aumento resultante del costo operacional del agua ha obligado una alta eficiencia de aplicación, lograda con tecnología agrícola, especialmente en productos de exportación. Estos avances técnicos aún no se aplican al riego urbano.

Chile fue uno de los primeros países que regó artificialmente en forma masiva casi toda su zona árida susceptible de riego (limitada por su disponibilidad de agua). En poco tiempo, agricultores y campesinos fueron resolviendo los problemas de operación y aplicación del agua, en especial en nuestros valles con suelos nada homogéneos, generando toda una tecnología que la ciencia validó posteriormente. Hoy, toda esa tecnología es un saber campesino, que conforma una de las pocas tradiciones culturales verdaderas del país: la tradición de riego. En otros países, la necesaria introducción del riego debe lidiar con largos programas de instrucción campesina.

"Alarife en hacer acequias y repartir aguas" se decía Pedro de Valdivia, como primer acto fundacional. La tradición de riego chilena, resultado de siglos de prueba y error, es la base cultural de la normativa técnica y legal que se aplica día a día para administrar nuestras zonas áridas.

\section{Diseño urbano en zonas áridas: aspectos hídricos}

Nuestro diseño urbano inicial atendió muy preferentemente todos los temas relacionados con el agua, desde los primeros días de la Conquista española, pasando por toda la Colonia, y buena parte de la República. A partir de la desaparición de la casa - huerto y la instalación de las redes de agua potable y alcantarillado en cada ciudad, esta atención fue decreciendo en todos los aspectos, para terminar siendo sólo una suma de exigencias incómodas, impuestas a los nuevos urbanizadores por muchos organismos mal coordinados, los que demasiadas veces deben aceptar anomalías de hecho. Otros aspectos simplemente se olvidaron, con grave impacto en la calidad de vida urbana, como es el caso del riego urbano: nuestras ciudades vuelven a ser el semi - desierto que precedió al riego.

A continuación, se presentan algunos antecedentes sobre los aspectos hídricos relacionados con el diseño urbano en zonas áridas.

Sobrepoblación de las zonas áridas regadas De los $749.000 \mathrm{~km}^{2}$ de superficie del Chile continental, la mayor parte no es habitable: uno se resbala, se congela o se fríe. Considerando que es habitable sólo el territorio potencialmente arable, de apenas 4,25 millones de ha $(<6 \%)$, resulta que Chile tiene una alta densidad de población de 3,7 habitantes por hectárea habitable, similar a Japón y algo mayor que Italia.

Dado su clima más amable, la mayor parte de la población del país se concentra en la zona árida regada, con pueblos que crecen uno cerca del otro: Santiago ha consumido nada menos que el $10 \%$ de la mejor superficie de riego del país (100.000 ha). El planeamiento urbano debe abordar estos hechos demográficos y territoriales, que son su origen, y repensar la ocupación urbana de nuestros escasos y 


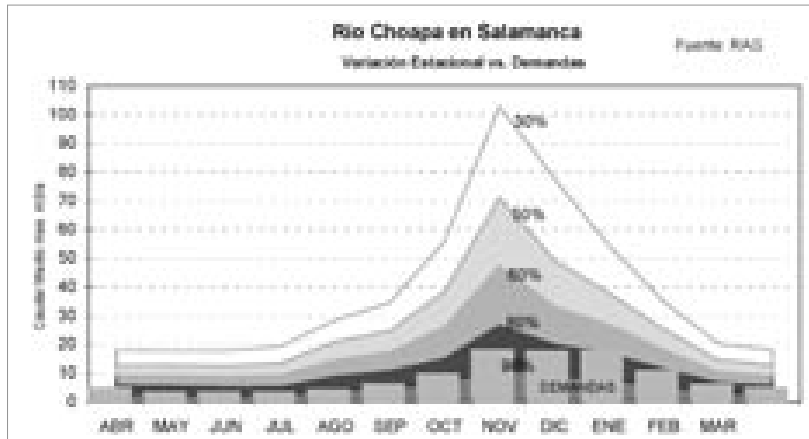

excelentes suelos regados.

El cuadro siguiente presenta algunas densidades de población por superficie potencialmente arable: (tabla 3)

Demandas urbanas de agua Las demandas urbanas de agua son de aproximadamente 200 1/ hab/ día sin riego de jardines; incluyéndolos, puede subir hasta $600 \mathrm{l} / \mathrm{hab} /$ día; éstos consumen $870 \mathrm{l} /$ día por $100 \mathrm{~m}^{2}$ (tasa de riego de 1,0 l/ seg/ ha). El riego veraniego de la forestación urbana de veredas debiera consumir $3.500 \mathrm{l} /$ día por manzana $(0,05 \mathrm{l} / \mathrm{seg} /$ ha urbanizada), equivalente al consumo de 3,5 departamentos.

Actualmente, las nuevas poblaciones de Santiago que ocuparon suelos de riego, consumen menos de un $30 \%$ del agua que disponían dichos suelos, prueba de un consumo sólo doméstico y sin ningún riego (dado el alto costo del agua potable, ¡mayor en el verano!).

Espacio propio de los cauces naturales y artificiales: drenaje y crecidas $\mathrm{El}$ alto precio de los terrenos urbanos ejerce una fuerte presión sobre los terrenos de nadie, como los cauces urbanos de ríos, esteros y quebradas. Al urbanizar, nadie quiere recordar que la faja propia de los canales artificiales es de a lo menos 2 veces su ancho; se los destina a fondos de patio o se entuban, llenándose de basuras. Las antiguas acequias de desagüe simplemente se eliminan. Como resultado, con lluvias mínimas las ciudades colapsan, con daños reales a sus habitantes. Como se dijo, el espacio que requieren los ríos es aquel que permita conducir su crecida centenaria más las piedras que ella arrastra (más de 100.000 $\mathrm{m}^{3}$ por crecida). Una pérdida de ancho se traduce en menor capacidad para conducir dichas piedras, las que se embancan generando desbordes muy dañinos a la población (los ríos rellenaron el valle, por lo que corren por su parte más alta, y los desbordes se alejan de éstos).

Los esteros y quebradas del valle suelen ser sus cauces de drenaje natural. Su eliminación o reducción al mínimo no impide que las aguas sigan accediendo hacia ellos.

La tendencia mundial actual es generar amplios parques en torno a los ríos, parte de ellos inundable durante crecidas, con un diseño bastante específico (natural channel design), y con una adecuada solución de continuidad tanto aguas arriba como aguas abajo. Lo mismo con los esteros de desagüe y drenaje. Los canales de riego pueden ser un aporte urbano en el bandejón central de una calle; la forestación urbana en torno a estos cauces sí prospera, solucionando los graves daños de eventuales crecidas (que siempre ocurren) o de cada lluvia, con calidad de vida.
Sin embargo, la tendencia actual chilena es ocupar parte de los cauces urbanos existentes para solucionar el tráfico, y otra parte como botaderos de escombros (que luego se urbanizan).

Evacuación y tratamiento de aguas servidas Nuestras ciudades siempre evacuaron sus aguas servidas a cauces naturales, donde se producía un tratamiento natural apoyado por un suficiente caudal de dilución, fuertes pendientes del cauce (oxigenación) y abundantes días de sol (radiación UV). Las mayores demandas de agua han restado caudal continuo a los ríos, los que legalmente se secan cerca de la cabecera de los valles, para reaparecer mucho después en las zonas de afloramiento subterráneo. Esto ha obligado a buscar caudales de dilución cerca de la cordillera de la Costa, cuando se puede.

Otra tendencia mundial, apoyada por la FAO, es ocupar las aguas servidas de zonas áridas en el riego agrícola. Las raíces no absorben microbios ni bacterias, y la contaminación se produce sólo en la manipulación de las cosechas, lo que se controla. Por otra parte, el tratamiento natural de la materia orgánica de estas aguas al penetrar el suelo, resulta óptimo. El re uso de las aguas será una necesidad mundial, en especial en zonas áridas.

\section{Forestación urbana, áreas verdes y de esparcimiento}

En las zonas áridas, las ciudades debieran ser un oasis y no más secas y calurosas que su entorno. La forestación urbana, por ejemplo de Mendoza (Argentina), protege totalmente a la ciudad de la aridez colindante (a la sombra se conserva la humedad); Mendoza, con orgullo, crece con una ejemplar red de más de $500 \mathrm{~km}$ de acequias urbanas, que además colecta aguas lluvia.

En Santiago, los mejores árboles en veredas son los de las calles Lyon y Pedro de Valdivia, que continúan regándose semanalmente con sus acequias gracias a la porfía del ingeniero del canal San Carlos.

Por otra parte, en la medida que desaparecen los jardines interiores en poblaciones y departamentos, se hace indispensable la presencia de áreas verdes y de esparcimiento cercanas, inaceptables si son baldías. El problema que presenta una adecuada forestación urbana y de áreas verdes en Santiago es la ausencia de alguna red de abastecimiento de agua urbana que no sea la de agua potable. El alto costo del agua potable, sumado al mayor precio que adquiere en verano, produce el abandono de los árboles urbanos, antes cuidados por los vecinos. Por otra parte, las antiguas acequias de riego en las veredas eran tapadas por los nuevos y múltiples accesos de autos a sus predios; el agua desbordaba a las calles, por lo que los municipios las eliminaron.

\section{Proposición. Uso urbano de \\ las aguas servidas}

La otra red urbana que cuenta con agua en cada rincón de las ciudades, y que no es la del agua potable, es la red de alcantarillado. Creo que debe investigarse un diseño de micro - planta de tratamiento con una micro - impulsión, que en horas abundantes riegue por goteo de subsuelo a los árboles de cada cuadra. Alguna universidad o privados podrían abordar este diseño, que estimo tiene futuro.

\section{Conclusiones}

En Chile manejamos nuestra aridez mediante una tradición de riego que la transformó en vergeles de cultivos mediterráneos; esto fue posible ya que gran parte del territorio local no ocupado es un almacenamiento nival de agua. Los espacios urbanos vuelven a ser un semi - desierto al abandonar esta tradición, a partir de la eliminación municipal de las acequias y el posterior alza del costo del agua potable de verano, a partir de los años 80 .

Desde el punto de vista de estos aspectos hídricos, cabe destacar la necesidad que el ordenamiento urbano en zonas áridas considere al menos las siguientes materias:

- Soluciones de largo plazo para las fajas ocupadas por los cauces naturales, con continuidad tanto aguas arriba y abajo, y anchos suficientes para la crecida centenaria y para el arrastre sólido asociado. Esta faja, en lo posible, debiera considerar parques (incluso inundables), y no vías ribereñas.

- Aprovechamiento de las depresiones naturales de desagüe natural como red abierta de aguas lluvia, con un cauce en un amplio bandejón central de una calle y solución de continuidad adecuada hacia aguas abajo (reservando las fajas a futuro).

- Abastecimientos de agua seguros y no competitivos con la agricultura, como pozos profundos o afloramientos de agua subterránea.

- Reuso de las aguas servidas urbanas en el riego agrícola, con algún tratamiento primario.

- Soluciones para el riego de la forestación urbana, áreas verdes y de esparcimiento, independiente de la red de agua potable. Puede involucrar la conservación de la red de antiguos canales y acequias agrícolas, u otras a investigarse desde las aguas servidas.

- Soluciones propias y adecuadas a cada caso, luego de un estudio global del territorio a intervenir, especialmente si son suelos regados. Las soluciones extranjeras o de otras zonas, usualmente traen en forma implícita otros objetivos, otras limitaciones y realidades locales. ARO 